\title{
Facial Palsy as Presenting Feature of Relapsing Polychondritis in Association with Myelodysplastic Syndrome
}

\author{
MUHAMMAD ABDUR RAHI M¹, PRATIK DEWAN², HASNA FAHMIMA HAQUE ${ }^{3}$, TANVIRA AFROZE SULTANA ${ }^{4}$, \\ AKM SHAHEEN AHMED ${ }^{3}$, KHWAJ A NAZI M UDDI N³
}

\begin{abstract}
Relapsing polychondritis (RP) is a rare systemic inflammatory disorder having predilection for cartilaginous structures specially ears, nose, joints and respiratory tract. Myelodysplastic syndrome (MDS) is an established association. Here we describe case history of a 60-year-old man who had episodic pain involving left external ear, throat and nose, hearing difficulty and lethargy for six months and right sided facial weakness of recent onset. He was anaemic, his left ear was distorted and there was right facial palsy. Investigations revealed him to be a case of RP in association with MDS. His pain and facial palsy improved with prednisolone.
\end{abstract}

Key words: facial palsy, myelodysplastic syndrome, relapsing polychondritis.

\section{Introduction}

Relapsing polychondritis (RP) is a disease of unknown etiology and is characterized by cartilage inflammation. It was first described by Jaksch-Wartenhorst in 1923 and the term "Relapsing Polychondritis" was adopted in 1960. ${ }^{1,2}$ RP can be isolated or secondary to malignancy, connective tissue diseases or other autoimmune diseases. ${ }^{3,4}$ Neurological involvement is uncommon. Here we describe a case of RP who first presented to us because of facial palsy.

\section{Case Report}

A 60-year-old man presented with right sided facial weakness for 3 days. He had 6 month history of recurrent episodes of pain and swelling of left pinna, each episode persisted for 35 days and responded to non-steroidal anti-inflammatory drugs (NSAIDs). He also had episodes of mild pain in throat and nose. He complained of hearing difficulty and generalized weakness but did not have any history of arthritis, fever, night sweats or weight loss.

The patient was moderately anaemic with normal vitals. His left ear was distorted (Fig 1a). Examination of the nervous system was normal except right sided lower motor neuron type facial nerve palsy (Fig 2). Other examination findings were unremarkable.

1. Department of Nephrology, BIRDEM

2. Department of Internal Medicine and Endocrinology, Square Hospitals Ltd

3. Department of Internal Medicine, BIRDEM

4. Department of Haematology, BIRDEM.

Correspondence: Dr. Muhammad Abdur Rahim, FCPS (Medicine), Assistant Professor, Department of Nephrology, BIRDEM General Hospital, Shahbag, Dhaka, Bangladesh. Email:muradrahim23@yahoo.com.

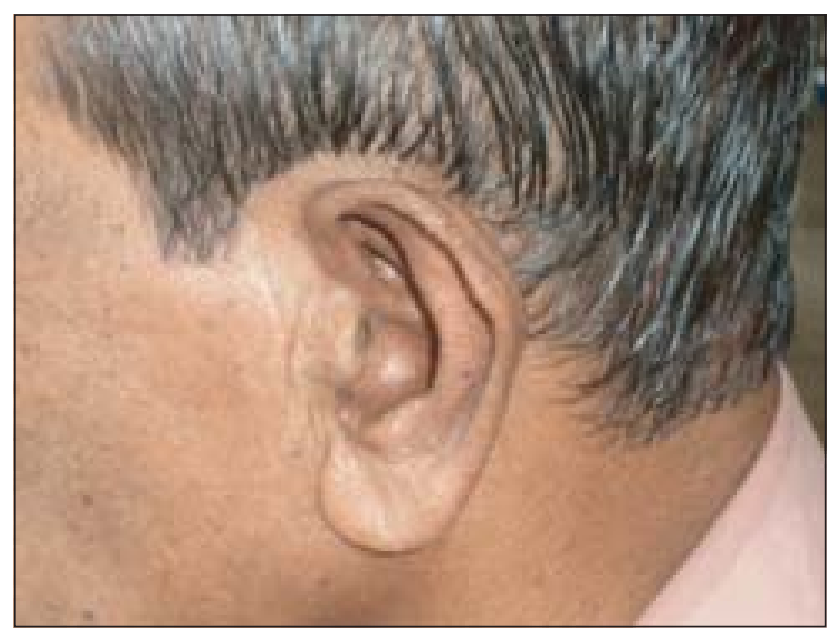

Fig.-1a: Distorded left ear specially helix and antihelix

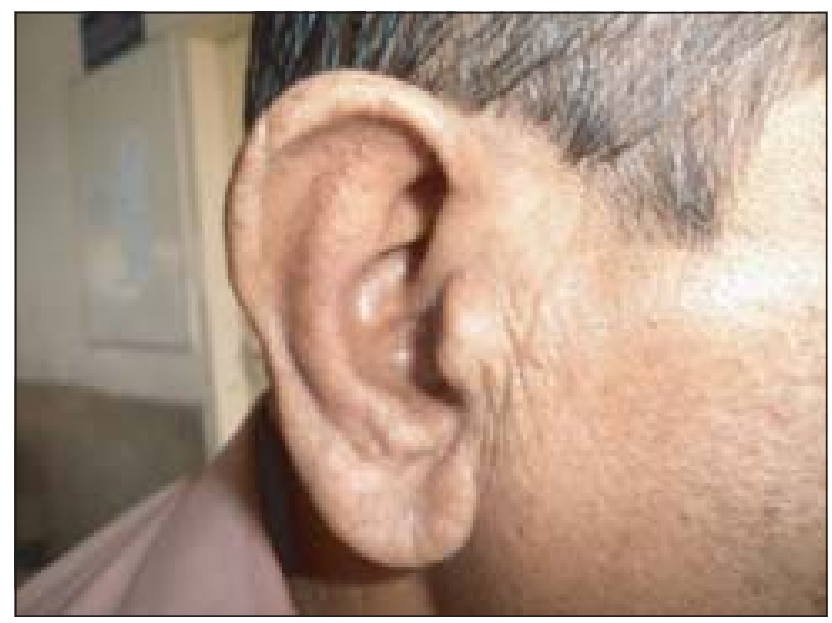

Fig.-1b: Normal right ear

His haemoglobin was $8.2 \mathrm{gm} / \mathrm{dl}$, normochromic-normocytic, total white cell count was $11,600 / \mathrm{cmm}$ with normal 
differentials, platelet count was 1,92,000/cmm, ESR $100 \mathrm{~mm}$ in $1^{\text {st }}$ hour and CRP $24 \mathrm{mg} / \mathrm{L}$ (less than 6). Blood film showed nonspecific morphology with mildly left shifted neutrophil leukocytosis. Urine routine examination did not show any red cell, protein or cast. Ultrasonogram of abdomen was normal as were liver and renal biochemistry including electrolytes. Rheumatoid factor, ANA and ANCAs were negative. Bone marrow findings were consistent with myelodysplastic syndrome (MDS); refractory anaemia with multilineage dysplasia (Fig 3a-d). Audiogram revealed bilateral mixed type of hearing loss. Histopthological examination of pinna revealed degenerative change (Fig 4).

He was finally diagnosed as a case of RP with MDS. Treatment was started with oral prednisolone at a dose of $0.5 \mathrm{mg} / \mathrm{kg} /$ day and he responded well.

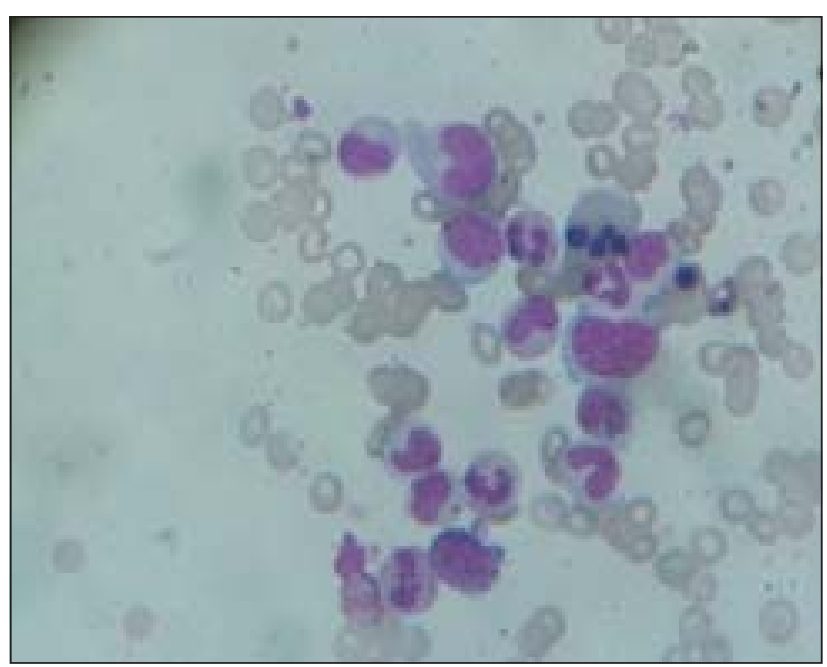

Fig.-3a: Bone marrow (BM) showing multinucleated erythroblast

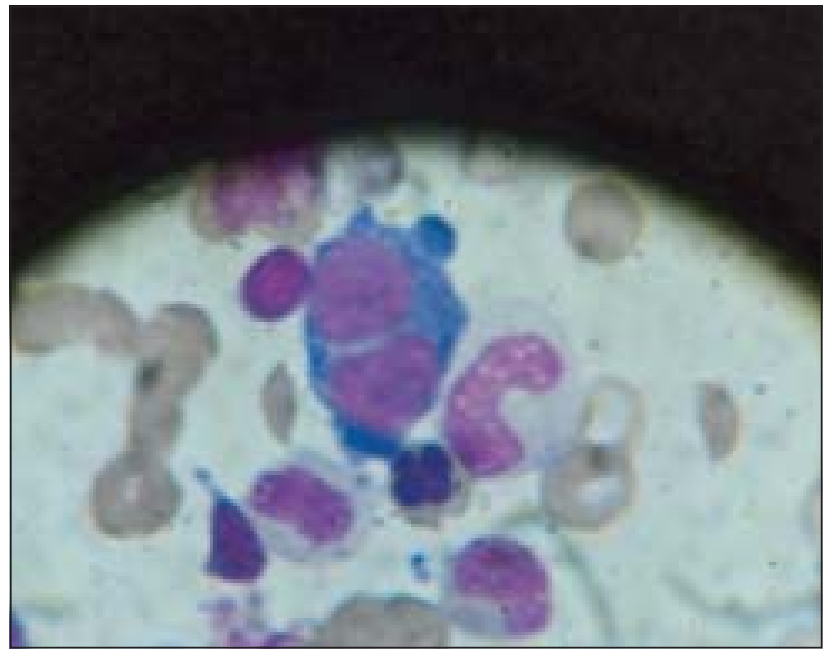

Fig.-3c: BM showing hypolobular megakaryocytes representing dysmegakaryopoiesis

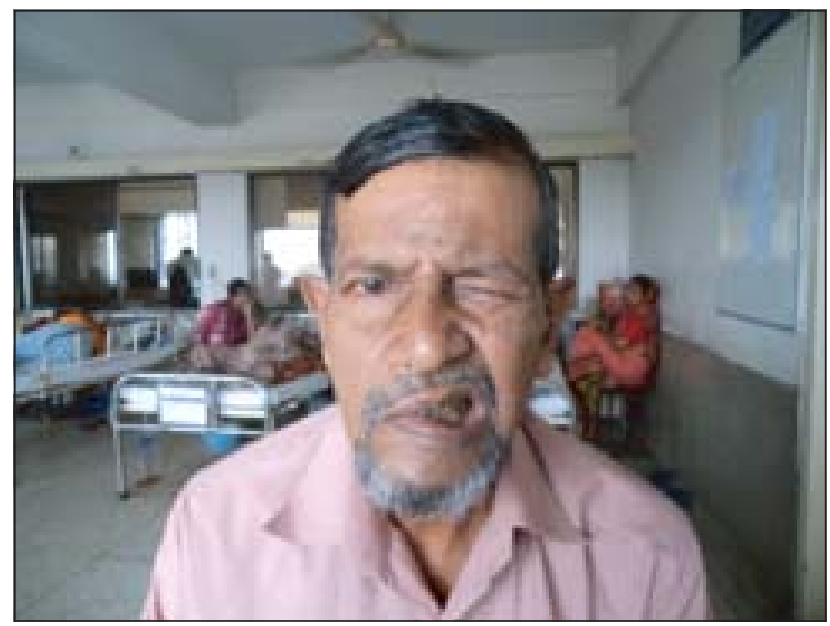

Fig.-2: Right sided facial palsy

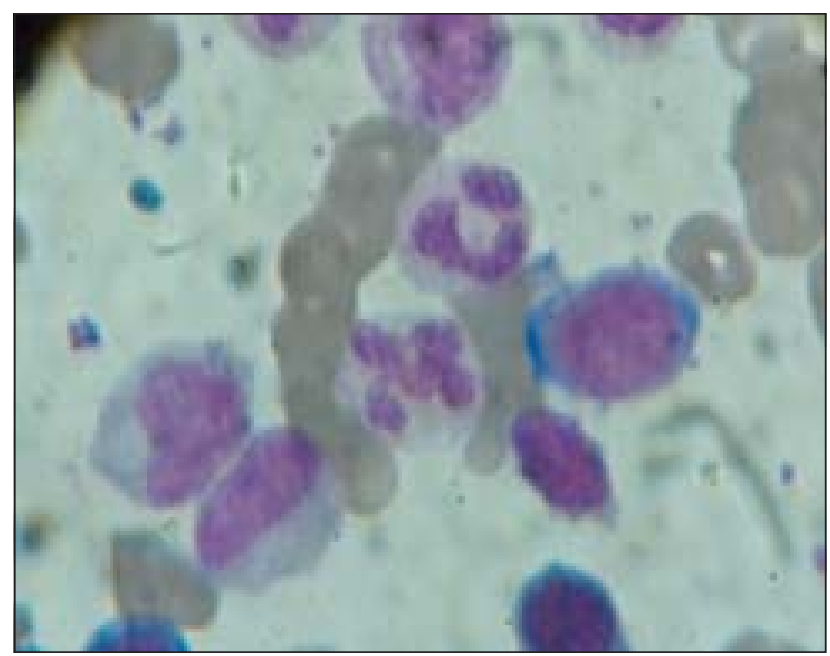

Fig.-3b: BM showing hypersegmented and hypogranulated neutrophil and megaloblast

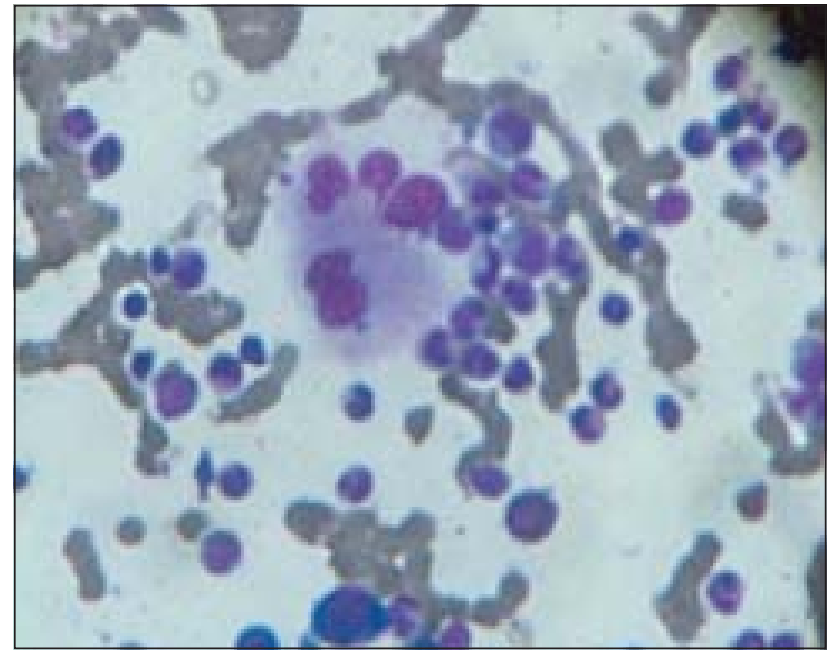

Fig.-3c:BM showing separated nucleoli representing dysmegakaryopoiesis 


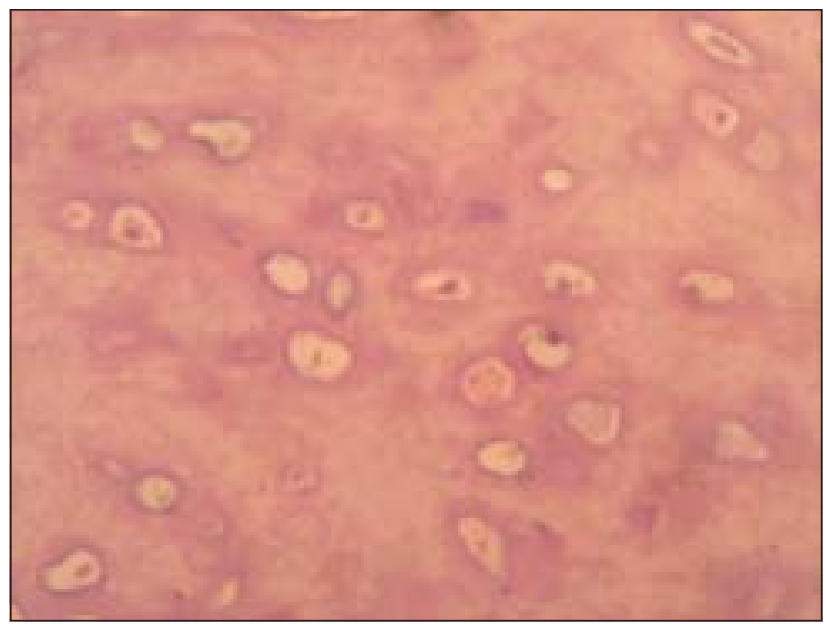

Fig.-4: Cartilage from pinna revealed degenerative vacuoles

\section{Discussion}

Diagnosis of RP is clinical and there are set criterias. ${ }^{5,6}$ Associated diseases are systemic vasculitis, rheumatoid arthritis, systemic lupus erythematosus, Sjogren's syndrome, spondyloarthritides, Behcet's disease, inflammatory bowel disease, primary biliary cirrhosis, myelodysplastic syndrome etc.

\section{Empiric Diagnostic Criteria for Relapsing Polychondritis ${ }^{5}$}

\section{Major Criteria}

Proven inflammatory episodes involving auricular cartilage Proven inflammatory episodes involving nasal cartilage Proven inflammatory episodes involving laryngotracheal cartilage

\section{Minor criteria}

Ocular inflammation (conjunctivitis, keratitis, episcleritis, uveitis)

\begin{tabular}{l}
\hline Hearing loss \\
\hline Vestibular dysfunction \\
Seronegative inflammatory arthritis \\
\hline $\begin{array}{l}\text { Diagnosis is made by two major criteria or one major } \\
\text { plus two minor criteria }\end{array}$ \\
- $\quad \begin{array}{l}\text { Histologic examination of affected cartilage is not } \\
\text { required }\end{array}$
\end{tabular}

\section{McAdam et al. criteria ${ }^{6}$}

Bilateral auricular chondritis

Nonerosive seronegative inflammatory polyarthritis

Nasal chondritis

Ocular inflammation

Respiratory tract chondritis

Audiovestibular damage

-Three of six clinical features necessary for diagnosis
Neurological features may be present in up to 9\% cases of RP and includes hemiplegia, cerebellar dysfunction, aseptic meningoencephalitis, polyneuritis, myelitis or cranial nerve palsy. ${ }^{7}$ By literature search we found few cases of RP who first presented with facial palsy. ${ }^{7-9}$ It may be debated whether facial palsy in our case was isolated Bell's palsy or not? We do believe that may it be so, but it is much more likely to be an association with RP. Another question may arise regarding absence of inflammatory cellular infiltrate of in histopathology of auricular cartilage. It is to be noted that biopsy is not mandatory for diagnosis of RP, moreover when patient agreed for biopsy there was no signs of active inflammation of pinna.

Malignancy is a common association of RP. Calistru AM et al. in a retrospective analysis of RP cases associated with Sweet syndrome found that $60 \%$ of cases were associated with malignancy or premalignant conditions and MDS was the leading cause occurring in $85 \%$ cases. ${ }^{3}$ Recently Haque MA et al. reported a case of RP from Bangladesh. ${ }^{10}$ But our patient was unique in that he had associated neurological features and MDS.

Treatment options for RP include corticosteroids, NSAIDs, methotrexate, hydroxychloroquine, colchicine, dapsone, salazopyrone, azathioprine and plasmapheresis in severe cases. The 5 and 10-year survival is $74 \%$ and 55\% respectively. Poor prognostic factors include saddle-nose deformity, systemic vasculitis and anaemia. Airway obstruction, pneumonia and cardiovascular involvement are main causes of death.

\section{Conclusion}

$\mathrm{RP}$ is an uncommon entity. Physicians should have high index of suspicion in appropriate clinical scenario and care should be taken to exclude associated disease(s), if present.

\section{Conflict of Interest: None}

\section{References}

1. Jaksch-Wartenhorst R. Polychondropathia. Wien Arch F Inn Med. 1923;6:93-100.

2. Pearson CM, Kline HM, Newcomer VD. Relapsing polychondritis. N Engl J Med. 1960;263:51-58.

3. Calistru AM, Lisboa C, Azevedo F. Paraneoplastic relapsing polychondritis and Sweet syndrome coexisting in a patient with myelodysplasia. Indian J Dermatol Venereol Leprol. 2011;77:730.

4. Chopra R, Chaudhary N, Kay J. Relapsing polychondritis. Rheum Dis Clin North Am. 2013;39(2):263-276. 
5. Michet CJ Jr, McKenna CH, Luthra HS, O’Fallon WM. Relapsing polychondritis: Survival and predictive role of early disease manifestations. Ann Intern Med. 1986;104: 74-78.

6. McAdam LP, O’Hanlan MA, Bluestone R, Pearson CM. Relapsing polychondritis: prospective study of 23 patients and review of the literature. Medicine. 1976;55:193-215.

7. Marie I, Martinaud O, Omnient Y, Mihout B. Facial diplegia revealing relapsing polychondritis. Rheumatology. 2005;44:827-828.
8. Van-Wermeskerken GK, Van-Den-Bergh WM, Frijns CJ. A man with painful red ear. Relapsing polychondritis. Ned Tijdschr Geneeskd. 2004;148(1):22.

9. Willis J, Atack EA, Kraag G. Relapsing polychondritis with multifocal neurological abnormalities. Can J Neurol Sci. 1984;11(3):402-404.

10. Haque MA, Tarik MH, Razzak MA, Ahmed KMA, Chowdhury ATH, Rahman MM. Relapsing Polychondritis: Case Report and Review of the Literature. J Medicine. 2014;15:80-83. 